\title{
Experimental restocking and seasonal visibility of a coral reef gastropod assessed by temporal modelling
}

\author{
Steven W. Purcell ${ }^{1,2, *}$, Yuk W. Cheng ${ }^{1,3}$ \\ ${ }^{1}$ Department of Fisheries Western Australia (Research Division), PO Box 20, North Beach, Western Australia 6920, Australia \\ ${ }^{2}$ National Marine Science Centre, Southern Cross University, PO Box 4321, Coffs Harbour, New South Wales 2450, Australia \\ ${ }^{3}$ Present address: Washington State Department of Fish and Wildlife, 600 Capitol Way North, Olympia, Washington 98501-1091, USA
}

\begin{abstract}
Assessing the survival of restocked marine invertebrates is complicated by crypticity and seasonal visibility of animals at release sites. We investigated local enhancement of trochus Trochus niloticus (Gastropoda) on 3 coral reefs in Western Australia. 12000 tiny hatchery-produced juveniles, 1 to $4 \mathrm{~mm}$ basal shell width (BSW), were released onto each of 4 intertidal sites on each reef. Visual surveys were conducted at stocked sites and control sites on each reef at 3-monthly intervals. Juvenile trochus $<25 \mathrm{~mm}$ BSW hide within the reef matrix and are found rarely on the upper reef surfaces, so detectable enhancement was expected from 12 mo after release, when they would be at sub-adult size (25 to $50 \mathrm{~mm}$ BSW). Abundance estimates of wild sub-adults fluctuated seasonally, and appear related to heat stress; i.e. they tended to be more exposed on the reef surface in periods of higher cloud cover and/or lower temperature. A cyclical trend in the abundance of sub-adult trochus is attributed to seasonal variation in their visibility in censuses. Temporal changes in adult abundance showed no consistent pattern. Due to the lag in detecting stocking of sub-adults and the cyclical nature of population estimates, we tested stocking success using a nonlinear mixed-effects model. From 12 to 18 mo post-release, sub-adults at stocked sites were more abundant (54\% increase) compared to control sites. Although statistically significant, the absolute enhancement was small. Variation in the stocking effect among sites underscores the need for multiple sites in restocking. Releases of tiny, cultured trochus juveniles could be used to rebuild nucleus breeding populations for fishery restocking, but improved release methods leading to higher survival of juveniles are needed to make this approach cost-effective.
\end{abstract}

KEY WORDS: Restocking · Nonlinear mixed-effects models · Stock enhancement • Visual census · Fishery · Invertebrate

Resale or republication not permitted without written consent of the publisher

\section{INTRODUCTION}

Restocking holds promise as a tool for rebuilding some depleted fisheries, but stocking modality and cost-effectiveness should be evaluated (Molony et al. 2003, Bell et al. 2005). Through the release of cultured juveniles, restocking aims to actively form nucleus breeding populations which can then rejuvenate egg supply and recruitment to depleted stocks (Bell et al. 2008). Unlike stock enhancement, which aims to increase productivity of an operational fishery (Bell et al. 2005), the process of restocking involves 2 main steps: (1) interventions to build nucleus breeding populations at source sites, and then (2) replenishment of population densities in nearby areas through their natural reproduction. Prospective programmes should critically assess the success of both steps. Some sedentary invertebrates, especially mollusks, offer good opportunities for marine restocking owing to limited displacement of stocked animals and localised dispersal of their progeny (Bell et al. 2005, Bartley \& Bell 2008).

Attempts at large-scale stock enhancement of marine invertebrates have been mostly unprofitable, with the notable exception of scallops in Japan and New Zealand (Booth \& Cox 2003, Uki 2006). Consequently, mindsets have shifted to using captive-release for 
restocking (Bell et al. 2005) and a more critical appraisal of its effectiveness compared to alternative management interventions. Recent evidence indicates that restocking could be worthwhile for other marine mollusks, including abalone (Shepherd et al. 2000, Roberts et al. 2007, Hamasaki \& Kitada 2008), bay scallops (Murphy et al. 2005, Arnold 2008) and trochus (Purcell et al. 2004). Although aquaculture technology can permit the production of low-cost juveniles en masse for release, high rates of post-release mortality may countervail the advantages of this modality. Resource managers must know which life history stage is most cost-effective for stocking, how many individuals need to be released and whether few or many sites should be stocked.

Trochus niloticus Linneaus is a large, herbivorous topshell vetigastropod of tropical reefs through the Pacific and Eastern Indian Oceans. Important economically, trochus is fished artisanally for its shell, but is often heavily exploited and poorly managed (Nash 1993, Purcell 2004, Bartlett et al. 2009). Management has improved in many countries, in particular through the use of marine reserves, size limits and fishing closures (Purcell 2004, Lincoln-Smith et al. 2006, Bartlett et al. 2009). Reliable aquaculture methods have fuelled interest into using hatchery-produced juveniles for restocking depleted reefs.

Trochus have many predators such as fish (e.g. Labridae and Tetraodontiformes), crabs (e.g. Thalamita sp.), stomatopods (e.g. Gonodactylus sp.), predatory gastropods (e.g. Melo amphora) and turtles (Nash 1993, Isa et al. 1997, Dobson 2000). While survival is higher for large juveniles than small ones (Castell 1996, Crowe et al. 2002), large juveniles are costly to produce (Lee 1997a). In contrast, tiny (1 to $4 \mathrm{~mm}$ basal shell width [BSW]) juveniles can be produced in mass numbers at low cost (Lee 1997a, 1997b). Release of tiny juvenile trochus avoids maladaptation from long-term hatchery culture (Bell et al. 2005) and the mass numbers at which they can be produced may compensate for low survivorship.

Evaluating the survival of released juveniles is a complex task when animals cannot be marked (Hilborn 1998, Molony et al. 2003). Without tagging, the chance of natural recruitment at sites can confound the enhancement of populations from released animals (Blankenship \& Leber 1995, Bell et al. 2005). For siteattached marine invertebrates, a before-after-controlimpact (BACI) experimental design (Underwood 1992) is an alternative to mark-recapture methods (Munro \& Bell 1997, Bell et al. 2005, Bartley \& Bell 2008). However, tests of stocking success can be confounded by large variation in abundance estimates among sites or sampling periods (Hilborn 1998), necessitating more complex analyses for BACI designs.
This study aimed to test the initial step of restocking trochus breeding populations through a BACI experiment involving the mass release of tiny juveniles onto reefs of King Sound, Western Australia. The evaluation of stocking was based on the inference that the abundance of sub-adult trochus at stocked sites will be higher, in the long-term, than at control sites without stocking. Additionally, the monitoring of wild subadult trochus showed a cyclical pattern to their seasonal visibility on the surface of the reefs. Therefore, we employed nonlinear mixed-effects (NLME) models to test the enhancement effect, superimposed on those seasonal trends. This approach provided a robust test of stocking success and should prove useful for other ecological or fisheries data with a BACI structure and nonlinear temporal patterns.

\section{MATERIALS AND METHODS}

Trochus occur on intertidal coral reefs at the mouth of King Sound, Western Australia (WA) (Fig. 1), and are of key interest to fishers in the local Aboriginal communities. All reefs in this area have existing trochus populations, but a history of fishing pressure and lack of management has depleted many of them.

Site selection. Three fringing coral reefs at the mouth of King Sound were selected: One Arm Point Reef, Bowlan Reef and Cunningham Point Reef (Fig. 1). The 3 experimental reefs were chosen out of a large range of potential reefs because these were sites of historical fishing of trochus and were conducive to surveillance by Aboriginal community members. The reefs experience high, bi-daily tidal fluxes of up to 10 m (Purcell 2002), summer monsoonal rain and high air temperatures $\left(>40^{\circ} \mathrm{C}\right)$. The relatively large intertidal reef-flat habitats are exposed for 3 to $4 \mathrm{~h}$, twice a day, during spring tides. On each of the study reefs, 6 sites (each $50 \times 50 \mathrm{~m}$ ) were selected and marked on the seaward part of the contiguous reef flat. The habitat was similar among sites within reefs, with holes and crevices in the substratum for refugia.

Short macroalgal communities dominated the intertidal zone (Purcell 2002). Conspicuous predators of trochus at low tide were portunid crabs, stomatopods and several gastropod species, but predatory birds were uncommon on the reefs. Trochus niloticus and a number of other topshell species (Trochidae) occurred on the surface of all 3 reefs, particularly Angaria delphinus, Tectus fenestratus, Tectus pyramis and Trochus hanleyanus.

Experimental design. A 3-factor randomised block design was employed. Two blocks were assigned on each reef, thereby grouping 3 sites, 200 to $300 \mathrm{~m}$ apart, within each block. The blocking procedure paired 

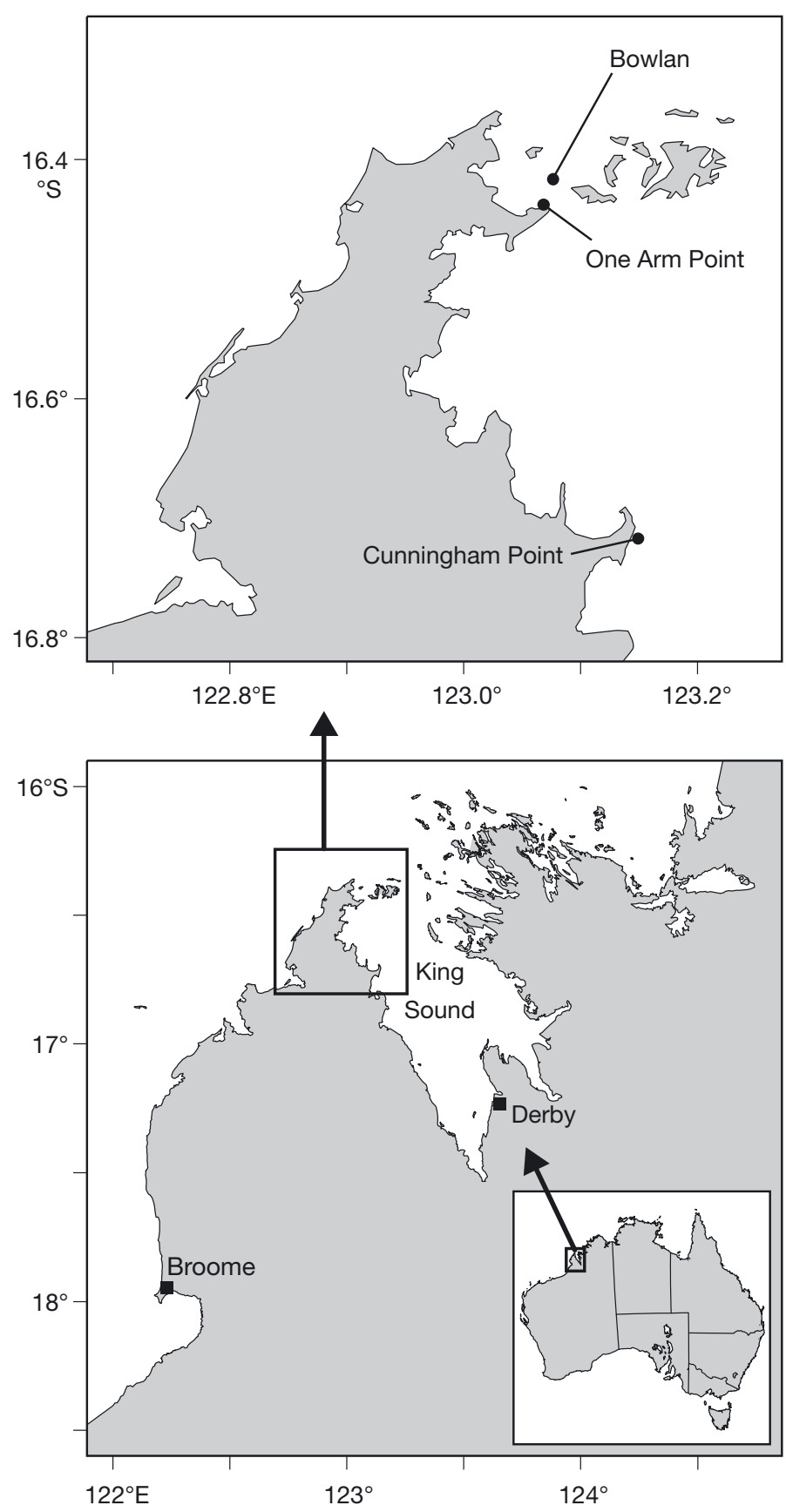

Fig. 1. West Kimberley region of Western Australia (below) and (above) the northern section of Dampier Peninsula indicating the positions of the 3 study reefs $(\bullet)$ for the juvenile stocking experiment

treatments in a way to potentially account for differences in abundance estimates attributed to the flooding and ebbing sides of each reef. The sites were nominated haphazardly and, within blocks, each site had a similar reef-flat microhabitat and was a similar distance from the low water mark of each reef. Sites were the unit of replication with repeated measures (counts

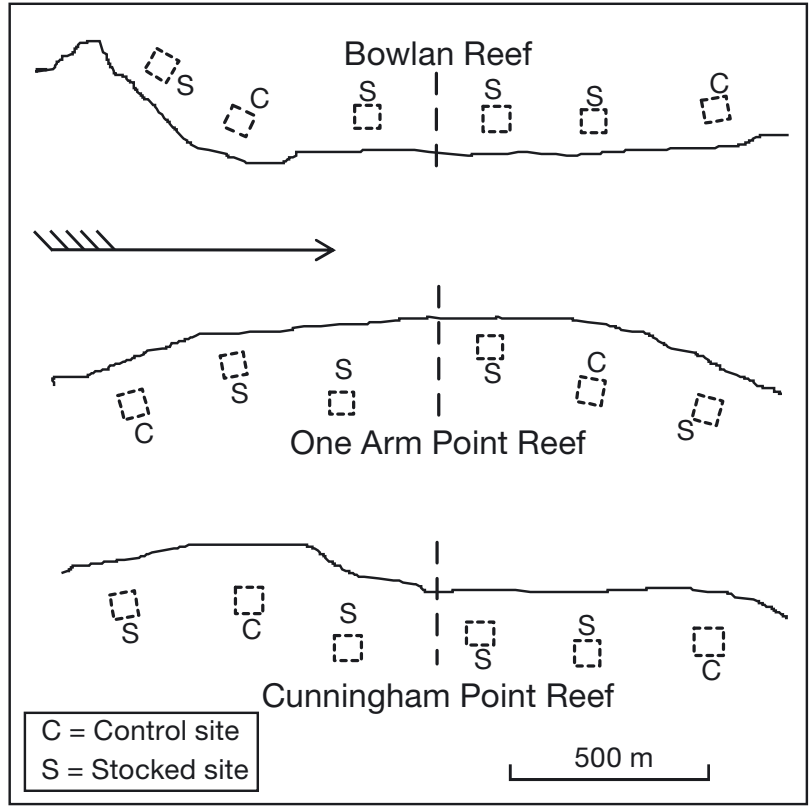

Fig. 2. Schematic diagram of the 3 experimental reefs, showing the arrangement of the $50 \times 50 \mathrm{~m}$ study sites (dashed boxes) within both blocks of each reef. Dashed lines indicate separation for reef blocks. The arrow denotes the direction of flooding tidal currents. Scale is approximate

of trochus summed across transects) over time, and site is considered a random effect because abundances would vary among sites, even within the same reef or treatment. Once marked, the 3 sites within each block were then assigned randomly to one of the following 3 treatments for the duration of the experiment: control, stocked and stocked + predator removal (using small traps). However, predator removal was abandoned after 3 mo due to ethical concerns, leaving an asymmetrical design of one control site and, effectively, 2 stocked sites per block (Fig. 2). Treatment and reef were fixed factors, while site was considered a random factor. 'Stocked' and 'control' refer to the spatial component (sites) and 'before' and 'after' refer to the temporal component (before and after stocking effects were detectable).

Preparation and stocking of juvenile trochus. Over 200 broodstock trochus (>75 mm BSW) were collected from offshore reefs near King Sound, broadly similar to those used in this experiment. They were induced to spawn using temperature shock (Lee 1997b) at a hatchery at One Arm Point (Fig. 1) in early August and early September 1999. Within 3 to $7 \mathrm{~d}$, the lecithotrophic larvae settled naturally onto dead coral rubble conditioned with cultured benthic diatoms (Nitzschia frustulum and Navicula sp.) (Lee 1997a). Juveniles were grown in tanks for 3 to $4 \mathrm{mo}$, attaining sizes of 1 to $4 \mathrm{~mm}$ BSW. The tiny juveniles were separated from the coral rubble in tanks by sieving through 
$8 \times 8 \mathrm{~mm}$ mesh screens and then placed into a rectangular, $3000 \mathrm{l}$ holding tank. We estimated a total of 146000 ( $\pm 34000 \mathrm{SE}$ ) juveniles through counts of replicate samples $(n=10)$ taken from the tank floor. To reduce variation in juvenile numbers among batches for stocking, the juveniles were carefully spread to an even thickness on the tank floor. The total area was then divided into 12 portions of equal area, yielding replicate groups of approximately 12000 juveniles for each stocked site.

Each group of juveniles was kept damp in holding bins and, on the following days (10-11 November 1999), was released at each stocked site. At low tide, the juveniles were scattered within an $8 \times 8 \mathrm{~m}$ area, centered on site markers, onto surfaces with coral rubble, holes and crevices for refuge. Patches of sand, deep tidal pools and areas with high cover of live coral were avoided. Soon after stocking, the juveniles were seen attached or moving on the reef surface. The high stocking densities were employed to concentrate stocking effects within the $2500 \mathrm{~m}^{2}$ (quarter hectare) reef sites for experimental purposes. Although the benthic habitat was suitable for juveniles and subadults (cf. Castell 1997) and individuals forage short distances from refugia (Castell 1996, Crowe et al. 2002), emigration of some released trochus could have led to underestimation of survival within sites.

Visual censuses. The numbers of resident trochus at each site were estimated around low tide from 06:00 to $12: 00 \mathrm{~h}$ at $0,1,3,6,9,12,15$ and 18 mo after stocking. At each census period, each $50 \times 50 \mathrm{~m}$ site was delineated by two $50 \mathrm{~m}$ measuring tapes.

Censuses of trochus at each site were conducted by walking along replicate $(n=12)$ belt transects $(2 \times 50 \mathrm{~m})$, positioned by a priori randomisation, perpendicular to the seaward edge. Observers walked along transects at 6 to $8 \mathrm{~m} \mathrm{~min}^{-1}$ using a $2 \mathrm{~m}$ wide $\mathrm{T}$-bar to delineate the transect width. The BSWs of trochus sighted within transects were recorded into $10 \mathrm{~mm}$ size classes. Six to 8 consecutive days during spring tides were used to census all 18 sites for each survey period, varying the order of sites.

Replicate censuses $\left(\mathrm{n}=12\right.$ ) using $0.5 \mathrm{~m}^{2}$ quadrats were also carried out at $\mathrm{T}=0,1$ and 3 mo periods to estimate the abundance of trochus of BSW $<25 \mathrm{~mm}$. The holes, coral rocks and algal communities within each quadrat were searched for $2 \mathrm{~min}$, but no juveniles (BSW $<25 \mathrm{~mm}$ ) were found so quadrat censuses were discontinued. Juvenile trochus appear to live in holes within the reef matrix until at least $25 \mathrm{~mm}$ BSW in size (Magro 1997a, Crowe et al. 2002). Considering growth rates of 2 to $2.5 \mathrm{~mm} \mathrm{BSW} \mathrm{mo}^{-1}$ (Nash 1993, Bell et al. 2005), potential enhancement would not be expected to be apparent until 12 mo from stocking when they would be within sub-adult size (25 to $50 \mathrm{~mm}$ BSW).
Series of duplicate censuses were carried out to determine if some trochus on the reef surface were missed by the observer. When time permitted, one observer censused trochus along a randomly placed measuring tape. Two other observers then censused the same transect at approximately $4 \mathrm{~m} \mathrm{~min}^{-1}$ to provide a test of the census accuracy, assuming that they could find all trochus on the reef surface.

Data analyses. We used multiple regression to examine the relationship between the mean abundance of sub-adults (25 to $50 \mathrm{~mm}$ BSW) at census times (data averaged across sites) and various environmental variables. Average monthly air temperature, maximum temperature flux, barometric pressure at sea level, relative humidity, cloud cover, wind speed (taken at 09:00 h) and total monthly rainfall were provided by the Australian Bureau of Meteorology. Data of average spring tidal flux over each census period were calculated from tidal data for Koolan Island $\left(16^{\circ} 08^{\prime} \mathrm{S}\right.$, $123^{\circ} 44^{\prime} \mathrm{E}$ ) from the Australian National Tide Tables, Department of Defence. Average monthly sea surface temperatures were obtained from CSIRO, Division of Marine Research, Perth. In the regression analysis, the first 6 highest absolute correlations between the response variable and the predictor variables were used. Akaike's information criterion (AIC), Bayesian information criterion (BIC) and corrected AIC (AIC $)$ (Akaike 1974, Schwarz 1978, Hurvich \& Tsai 1989) were used to select the best regression model.

Stocking effects were tested using a NLME model, performed using S-Plus 2000 software. NLME models compare individual curves and group curves rather than group observations, as occurs with repeated measures ANOVA. The model accounts for the nonlinear detectable abundance of sub-adult trochus, fixed effects from experimental factors and random effects due to natural variations among sites. A dummy-variables technique was used to formulate the effects of block, reef and treatment in the NLME model. Block 1, Bowlan Reef and the control treatment were used as the contrast for all the levels within each factor. Due to the 12 mo delay in detecting responses of the stocking treatment (stocked juveniles live in holes until > $25 \mathrm{~mm}$ BSW), sub-adults sighted at both stocked and control sites prior to 12 mo were considered to be wild animals. Consequently, 2 analyses using NLME models were performed.

In the first analysis, all data from 0 to 9 mo were used to determine an optimal nonlinear link function in an NLME model to describe the natural temporal fluctuation in observable abundance of sub-adult trochus. Data on counts of sub-adults within transects were summed within each site $\times$ time combination (i.e. 12 transects pooled) to provide the repeated measure for sample units. The iteration of various sine-curve func- 
tions in this stage revealed a function with the best fit (by comparing residual deviance of equations with the same number of unknown parameters) to the longitudinal data.

In the second analysis, the nonlinear function of that model was then applied in a further NLME model, using data from all time periods, to test for a stocking effect. In this test, data prior to 12 mo were assigned to the 'before' time period and from 12 mo onwards to the 'after' time period; effectively, a 'before-and-after' comparison. The potential for a significant interaction between reef and treatment effects was rejected by finding that the NLME model function provided a close fit to data for all reef $\times$ time period combinations. The NLME model thus assumes no higher order interactions between the effects of block, reef and stocking treatment, and that there were random effects from sites. The constant $\left(a_{0}\right)$ was included in the model to estimate the annual maxima in sub-adult abundance, and the constant $\left(e_{0}\right)$ was included to determine the specific timing of the minima of the sine curves. The NLME model on the response variable - the frequency of sub-adult trochus - took the form:

$Y_{i j k l m}=a_{0}+\alpha_{i j k l} \times \sin ^{2}\left[\frac{\left(t_{m}+e_{0}\right) \pi}{12}\right]+b_{i}+c_{j}+d_{k}+\varepsilon_{i j k l m}$

where $y_{i j k l m}$ is the result from reef $i$, block $j$, treatment $k$ and replicate $l$ in month $m_{i} \alpha$ is a random effect of the maximum detectable annual abundance (amplitude) of trochus; $b_{i}$ is the effect of reef $i_{i} c_{j}$ is the effect of block (half reef) $j_{i} d_{k}$ is the effect of the treatment (control or stocked) $k$ at the first (and second) year in the first (and second) analysis; $a_{0}$ and $e_{0}$ are constants to be determined; and $\varepsilon_{i j k l m}$ are errors with the assumptions:

$$
\varepsilon_{i j k l m} \sim N\left(0, \sigma_{\varepsilon}^{2}\right)
$$

In this equation, $\alpha$ was modelled as a normal distribution with mean $\mu_{\alpha}$ and variance $\sigma_{\alpha}^{2}$. This NLME model effectively fits a sine curve for abundances of trochus before and after the stocking effects for each control and stocked site. The average difference in the mean $\alpha_{\mathrm{ijkl}}$ between stocked and control sites, from before to after stocking effects could be detected, provides the estimated average change in numbers of trochus due to stocking. The error vector $\varepsilon_{i j k l}$ with dimension $1 \times m$ was assumed to be distributed as $N\left(0, \sigma^{2} \varepsilon_{i j k l}\right)$. The choice $\varepsilon_{i j k l}=\mathrm{I}$, where I is the identity matrix, corresponds to the case of no serial correlation. We applied the likelihood ratio test to test whether the random effects were significant or not. We used an AR(1) error structure (Jones 1981, Jones \& Boadi-Boateng 1991), which is often more realistic since it allows serial correlation in continuous time series models. Similarly, the likelihood ratio test was employed to test the significance of the AR(1) error structure. In addition to the tests on data of sub-adult abundance, data pooled for all adults (BSW $>50 \mathrm{~mm}$ ) were also iterated using different types of possible functions for analyses using an NLME model. The various functions were tested to see if there were any consistent seasonal or longitudinal patterns in adult abundance at sites.

\section{RESULTS}

\section{Demography of wild trochus}

In a total of 1728 transect censuses, the BSWs of 3295 trochus were measured and recorded, although some of these records were likely to be individuals remeasured at different times. A total of $639(19.4 \%)$ of these records were of sub-adults (25 to $50 \mathrm{~mm} \mathrm{BSW}$ ) and the rest (except 3 ) were adults (BSW $>50 \mathrm{~mm}$ ). Importantly, only 3 juveniles (BSW $<25 \mathrm{~mm}$ ) were found. Other intertidal habitats on the reefs were also searched during the study, but juveniles were not found in any zone, except occasionally under large boulders on the reef surface. A few standardised searches at night at each reef also failed to locate juveniles. Castell et al. (1996) and Crowe et al. (2002) also showed that juvenile trochus shelter from upper reef surfaces. Apart from at high latitudes, trochus spawn serially through the year (Nash 1993), so the inability to locate juveniles in the present study was likely not attributable to irregular recruitment.

Trochus were found commonly on Bowlan Reef, but were found in lower abundance on One Arm Point Reef and in even lower abundance on Cunningham Point Reef. The abundance of sub-adults at sites on Bowlan Reef and One Arm Point Reef were low at the commencement of the experiment and fluctuated through time (see 'Stock enhancement and seasonality').

Most of the trochus that could be potentially sighted on the reef surface were found using the transect census method, i.e. by one observer walking at 6 to $8 \mathrm{~m}$ $\mathrm{min}^{-1}$. The paired censuses showed that the percentage accuracy of censuses was high and differed between observers (Table 1). The survey methods did not appear to asymmetrically overlook small individuals, since only 33 and $58 \%$ (by observer A and $\mathrm{B}$, respectively) of the few animals undetected by the singleobserver searches were sub-adults (Table 1).

\section{Sub-adult abundance versus environmental variables}

All the estimated coefficients of the 6 predictor variables and the intercepts were non-significant (Student's $t$-test, $\mathrm{p}>0.7, \mathrm{df}=1$ ) in separate linear regressions with 
Table 1. Trochus niloticus. Summary statistics of accuracy of the census technique of a single observer compared to dual observers. Number of trochus found by dual observers is taken as the total number present. Relative undersighting bias is the proportion of individuals in either size class out of the few additional individuals found by dual observers (i.e. proportion of the additional sub-adults or adult trochus found by dual observers). Sub-adults: basal shell width (BSW) 25-50 mm; adults: BSW > $50 \mathrm{~mm}$

\begin{tabular}{|c|c|c|c|c|c|c|}
\hline \multirow[t]{2}{*}{ Observer } & \multirow[t]{2}{*}{$\mathrm{n}$} & \multicolumn{2}{|c|}{$\begin{array}{l}\text { Mean no. of ind. } \\
\text { per transect }\end{array}$} & \multirow[t]{2}{*}{$\begin{array}{c}\% \text { accuracy } \\
( \pm \mathrm{SE})\end{array}$} & \multicolumn{2}{|c|}{$\begin{array}{c}\text { Relative } \\
\text { undersighting bias }\end{array}$} \\
\hline & & Found & Present & & Sub-adults & Adults \\
\hline A & 9 & 10.7 & 11.0 & $97 \pm 4$ & 0.33 & 0.67 \\
\hline B & 4 & 7.8 & 10.5 & $74 \pm 10$ & 0.58 & 0.42 \\
\hline
\end{tabular}

$\mathrm{df}=6$ ). Both cloud cover and air temperature varied seasonally (Fig. 3) and the final regression model indicated that, in combination, these were marginally significant $(F=5.73, \mathrm{p}=0.05, \mathrm{df}=2$ and 5 , respectively) in explaining $70 \%$ of the variation in sub-adult abundance among survey times (multiple $\mathrm{r}^{2}=0.70$ ).

\section{Stock enhancement and seasonality}

The first NLME model analysis of data before 12 mo by maximum likelisub-adult abundance as the response variable. The estimated coefficient of correlation among the 6 predictor variables (before model selection) varied from 0.97 to -0.97 . For the selected multiple regression model, the correlation of sub-adult abundance with the environmental variables varied from -0.51 to 0.26 . Cloud cover and air temperature $(\mathrm{r}=0.26$ and -0.42 , respectively) were most important in explaining subadult abundances in the final multiple regression analysis from AIC model selection. BIC and $\mathrm{AIC}_{\mathrm{C}}$ methods resulted in the same model selection as AIC. Subadult abundances were significantly positively related to cloud cover (estimated coefficient slope $=1.13, \mathrm{p}=$ 0.03, df $=5$ ) and significantly inversely related to air temperature (estimated coefficient slope $=-0.77, \mathrm{p}=$ 0.02 , df $=5$ ). There was a possibility of collinearity between the 2 predictor variables $(r=0.66)$; however, linear regressions refitted for each predictor variable with and without intercept revealed non-significant coefficients and intercepts (Student's $t$-test, $\mathrm{p}>0.17$,

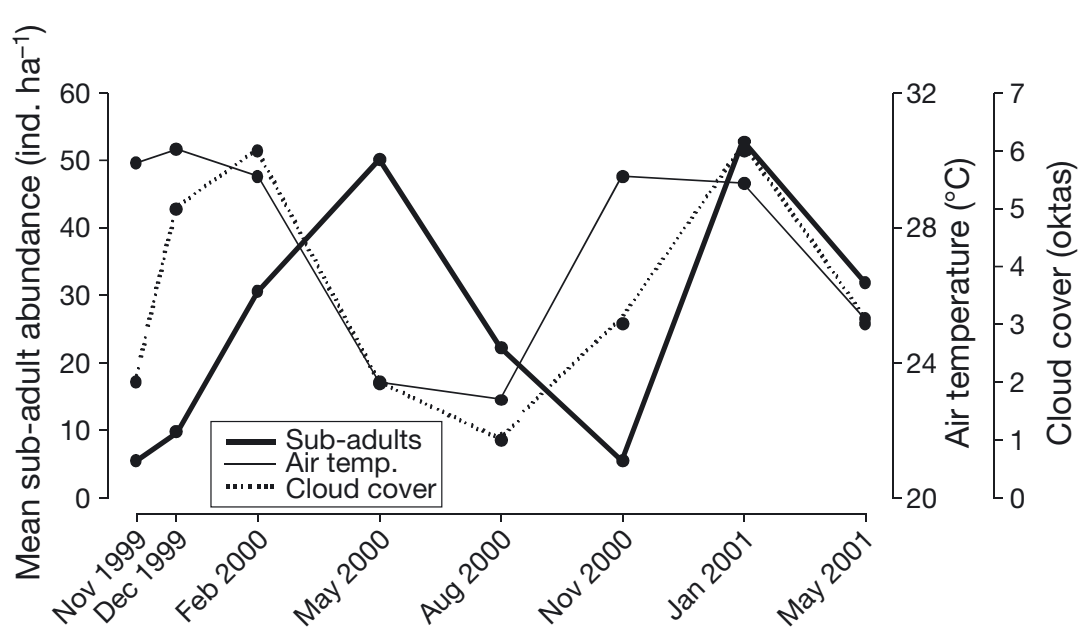

Fig. 3. Trochus niloticus. Line plots of average abundance of sub-adults (pooled among sites), cloud cover and air temperature (09:00 h, monthly averages) for the study location over the 18 mo census period. Error bars are not plotted to avoid clutter, but cloud cover and air temperature were identified as important predictor variables from multiple regression analyses hood (ML) indicated that abundances of sub-adults did not differ significantly between stocked and control sites (Student's $t$-test, $\mathrm{p}=0.09, \mathrm{df}=70$ ). That is, subadult trochus were similarly abundant at stocking and control sites in the 'before' period. The effect of block was non-significant $(\mathrm{p}=0.48, \mathrm{df}=70)$, so this factor was removed to yield more powerful tests. The second analysis of the complete data set by ML showed that, in the 'after' period from 12 to $18 \mathrm{mo}$, sub-adult abundances were significantly higher at stocked sites than control sites ( $p<0.01$; Table 2$)$. Plots of the sine function, fitted to data for each site, show close correspondence to the abundance data (Fig. 4), as confirmed from inspection of residuals.

The effect size of 1.99 sub-adults for summed transects $\left(1200 \mathrm{~m}^{2}\right.$; Table 2$)$ equates to an average increase, over the 12 to 18 mo period, of $4.14( \pm 1.57 \mathrm{SE})$ sub-adults at stocked sites (quarter hectare) compared to the natural abundances at control sites (see 'Materials and Methods: Data analyses'). At many of the sites few trochus were recorded, so this increase translates to an average enhancement in sub-adult numbers at release sites of $54.3 \%$ when compared to the average abundance of wild subadults at control sites. This estimate is calculated from the average difference in amplitude of modelled sine curves between 'before' and 'after' time periods at stocked sites compared to the same average difference at control sites. While there appeared to be no significant interaction between stocking and reef factors, the absolute enhancement was apparently more pronounced at Bowlan Reef (Fig. 4a).

Further, the differences in abundances among reefs were greater than the average stocking treatment effect (Table 2) and Bowlan Reef had significantly more sub-adults than reefs at One Arm 
Table 2. Trochus niloticus. Results of nonlinear mixed-effects (NLME) model analysis of differences in abundance (summed across transects) of sub-adult trochus, considering data from stocked sites from 0 to 9 mo to reflect wild animals only (i.e. the 'before' time period). The time shift is the number of months that the start of the experiment $\left(\mathrm{t}_{\mathrm{m}}=0\right)$ is situated from the annual minima (in sub-adult abundance), along the modelled sine curve. Mathematical symbols of source factors follow those used in the NLME equation in 'Materials and methods: Data analyses'. The df of residual SE is 123

\begin{tabular}{|lccc|}
\hline Source & $\begin{array}{c}\text { Average }( \pm \mathrm{SE}) \\
\text { effect size }\end{array}$ & $t$ & $\mathrm{p}$ \\
\hline Stocking treatment $\left(d_{1}\right)$ & $1.985 \pm 0.753$ & 2.636 & 0.0095 \\
Reef $\left(b_{1}\right)$ & $3.581 \pm 0.893$ & 4.011 & 0.0001 \\
Amplitude (of sine curve) $(\alpha)$ & $5.819 \pm 2.185$ & 2.663 & 0.0088 \\
Time shift $\left(e_{0}\right)$ & $0.627 \pm 0.179$ & 3.499 & 0.0006 \\
\hline
\end{tabular}

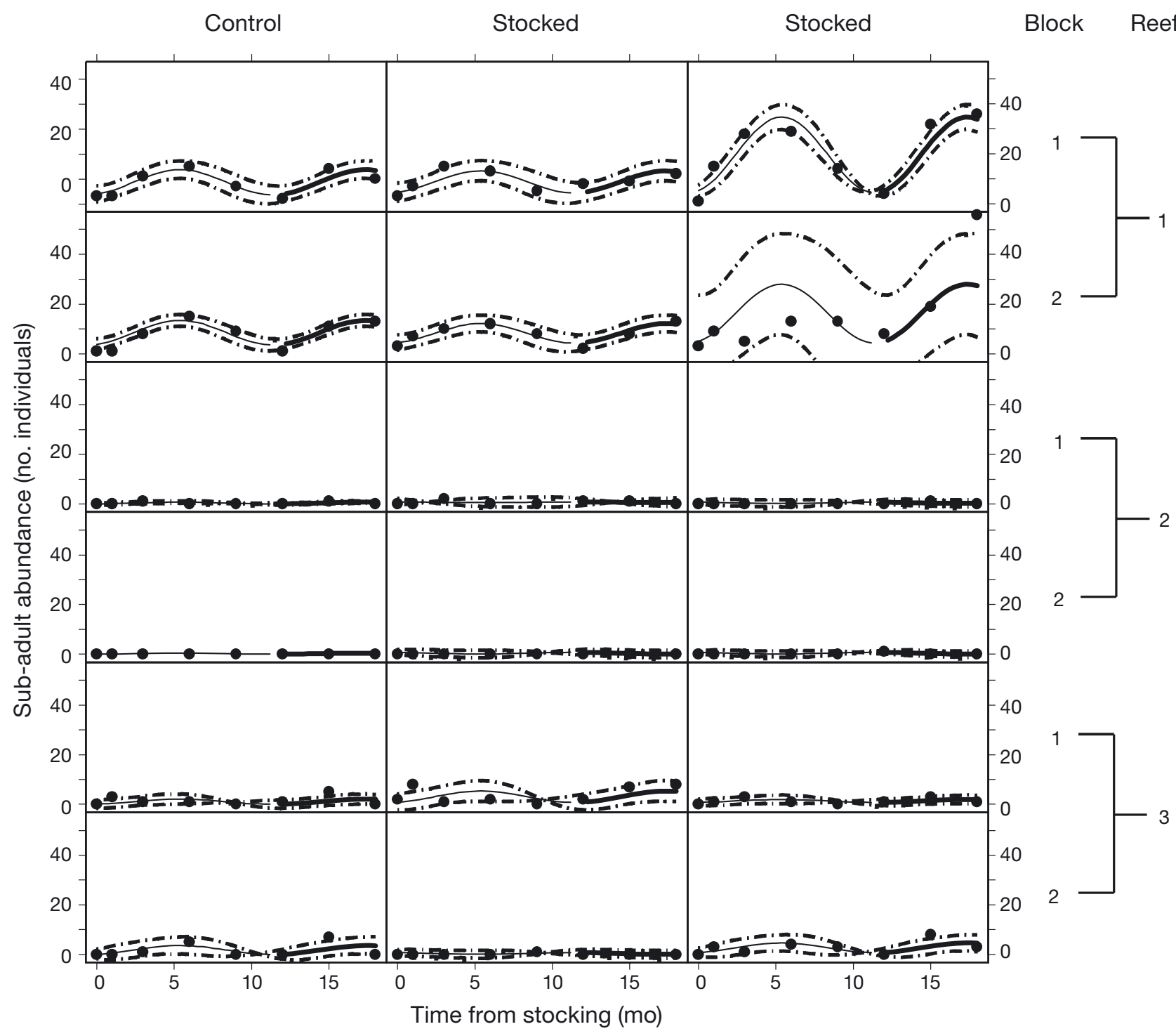

Fig. 4. Trochus niloticus. Modelling sub-adult abundance. Solid dots are abundances of sub-adult trochus (25-50 mm basal shell width) summed across transects at each site. Solid sine curves model the temporal trends at each site based on the function used in the second nonlinear mixed-effects model analysis; dashed lines are $95 \%$ CI. Bold sine curves denote the same temporal trend in the 'after' time period (12 to $18 \mathrm{mo}$ ). Reef 1: Bowlan Reef; Reef 2: Cunningham Point Reef; Reef 3: One Arm Point Reef
Point or Cunningham Point $(\mathrm{p}<0.001)$. The difference in abundance between Bowlan and the other 2 reefs equates to 7.46 sub-adults per site.

The analysis showed that the commencement of the experiment occurred at 0.63 mo from the minima of the modelled sine curve (Table 2). Using this timing improved the prediction of the data significantly (likelihood ratio test, $\mathrm{p}<0.001$, $\mathrm{df}=6$ to 5 ). The model indicates that abundances of sub-adults were lowest in late October and highest in late April. The Stocked Block Reef 


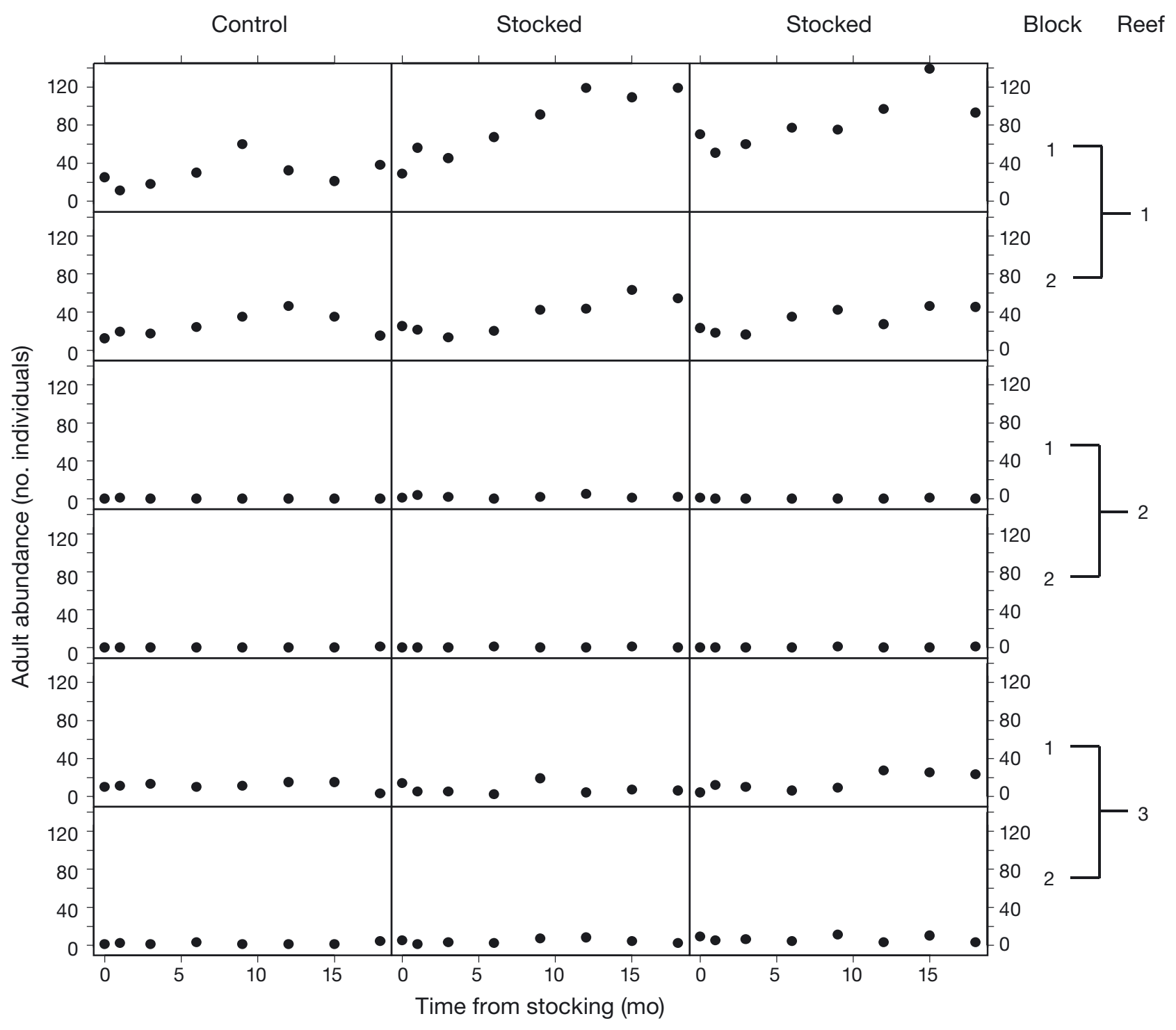

Fig. 5. Trochus niloticus. Modelling adult abundance. Solid dots are abundances of adult trochus (>50 mm basal shell width) summed across transects, showing inconsistent temporal variations among sites within and among reefs. Reef 1: Bowlan Reef; Reef 2: Cunningham Point Reef; Reef 3: One Arm Point Reef

inclusion of Site as a random effect in the model resulted in a statistically significant (likelihood ratio test, $\mathrm{p}<0.001$, $\mathrm{df}=6$ to 5 ) improvement on the likelihood of detecting a stocking effect. Inspection of residuals from the NLME model indicated no pattern against treatment or time (month).

The findings from the NLME model analyses on data of adult abundances differ from those found for subadults. Temporal patterns in abundance of adults varied within and among reefs (Fig. 5), and lacked the seasonal trends depicted for sub-adults. It was therefore not possible to model the temporal trends in adult abundances among sites.

\section{DISCUSSION}

\section{Effects of juvenile release}

Stock enhancement and restocking programs should firstly appraise the costs and benefits of the interventions (Hilborn 1998, Molony et al. 2003, Bartley \& Bell 2008) and then quantitatively assess stocking success (Leber 1999, Bell et al. 2008). Consistent with enhancement studies on abalone (Roberts et al. 2007, Hamasaki \& Kitada 2008), which also belong to the clade Vetigastropoda, we found high spatial variability in stocking effects in terms of increased numbers of sub- 
adult trochus at stocked sites. At some sites, the enhancement would have been too trivial to produce effective breeding populations. One could conclude that restocking trochus through the release of tiny juveniles will not be a universal remedy to restoring breeding populations at all target sites.

The apparent differences in enhancement among reefs in the present study reinforce the notion that large spatial variation can be expected in population enhancement using hatchery releases. It was unclear why enhancement was apparently greater on Bowlan Reef, and we believe that release groups of tiny juvenile trochus were homogenous. More likely, differences in predation, competition or habitat among reefs compromised the survival of juveniles. Predation, in particular, is considered as the most significant hurdle to survival of juveniles in stocking programmes (Bell et al. 2005, 2008, Bartley \& Bell 2008). Restocking of trochus breeding populations should therefore be conducted at multiple sites in the targeted fishery to mitigate poor survival of animals to adulthood (cf. Roberts et al. 2007) and potentially ineffective spawning success, at some sites.

The average estimated enhancement (4.14 subadults per quarter-hectare site) was based only on the number of sub-adults on the reef surface. However, it is likely that perhaps only 10 to $20 \%$ of sub-adults (ca. 1 to 2 yr old) were visible in surveys overall (see next subsection). Hence we postulate that the average total enhancement (including hidden sub-adults) would be on the order of 20 to 40 animals per site. While the numbers of surviving trochus at some sites could have been enough to form effective breeding populations for restocking, this extrapolation indicates a survival rate of $<1 \%$. Heppell \& Crowder (1998) cautioned that an increase in juvenile cohort size of late-maturing species does not necessarily increase population growth significantly. These results on sub-adult enhancement should therefore be interpreted cautiously, but we expect that many individuals would reach maturity and contribute to spawning of the population because the rate of predation on trochus declines sharply after animals reach a sub-adult size of about 25 to $40 \mathrm{~mm}$ (Vermeij 1976).

Trochus stocks can be enhanced by: (1) broodstock translocation (see Nash 1993), (2) release of sub-adults grown to $\sim 40 \mathrm{~mm}$ BSW in sea cages (Clarke et al. 2003, Purcell et al. 2004), and (3) stocking with tiny juveniles from the hatchery. In the present study, roughly 20 to 40 sub-adults per site and costs of production of tiny juveniles (Lee 1997a) gives estimates of about 3 to 6 USD per sub-adult surviving on the reef after 12 to 18 mo. For stocking abalone, release of button-sized juveniles appears to be a more cost-effective modality than dispersing larvae or tiny juveniles, despite higher hatch- ery costs (Heasman 2006). Perhaps the success in stocking trochus could be improved, for example, by stocking juveniles at lower density or acclimating them in biodegradable shelters prior to release (cf. Heasman 2006). Until such improvements can be proven, we posit that translocation of broodstock (within genetic distributions of the stock) or small-scale releases of small numbers sub-adults grown in sea cages (Purcell 2001, Purcell et al. 2004) may be more cost-effective modalities to stock trochus than mass releases of cheaper tiny juveniles.

\section{Ontogenetic niche shift}

The absence of juvenile trochus on the reef surface in the present study has also been reported for a range of intertidal reef habitats at King Sound (Magro 1997b, Colquhoun 2001). In the Indo-Pacific, trochus juveniles and sub-adults tend to occur on the reef flat and move to the reef crest and fore-reef slope as they reach maturity (Smith 1987, Castell 1997). In the present study, the entire intertidal zones were 'reef flat' habitat with no reef crest, and both sub-adults and adults occurred where juveniles were stocked.

Additionally, the relatively low frequency of subadults (25 to $50 \mathrm{~mm}$ BSW) compared to 60 to $80 \mathrm{~mm}$ BSW trochus indicates that most sub-adults probably hid in holes and could not be seen in surveys (cf. Castell et al. 1996, Crowe et al. 2002). The size distribution based on visual surveys was not biased towards smaller individuals, as would be expected from complete habitat sampling of comparable vetigastropods (see Prince et al. 1988, Tegner et al. 1989). In other words, in order to have small and medium-sized adult trochus on reefs annually there must be many (e.g. 5 to 10) times more juveniles and sub-adults present to permit enough to reach adulthood after mortality losses. This corollary suggests that trochus on these reefs have an ontogenetic niche shift to foraging on the reef surface, rather than in holes in the reef matrix, at about 30 to $40 \mathrm{~mm}$ BSW. Such behaviour is also found in the closely related Haliotidae (abalones), which hide under boulders on rocky reefs and move to exposed surfaces as they grow (Prince et al. 1988, Schiel 1993).

\section{Seasonality of sub-adult visibility}

Findings from previous studies support our conclusion that the seasonal fluctuations in the number of sub-adults recorded at sites were due to their cryptic behaviour, affecting their visibility on the reef surfaces. Juveniles and sub-adults are known to hide in holes and forage only short distances from refugia 
(Castell et al. 1996, Isa et al. 1997, Crowe et al. 2002). In addition, sub-adults inhabit the entire reef flat on reefs in King Sound, with no apparent spatial segregation of size classes (Colquhoun 2001). Thus the seasonality in abundance was unlikely to be due to periodic migration to, and emigration from, sites. Moreover, our data comprising sub-adults are likely to include individuals from more than one cohort and showed no indication that temporal fluctuations were due to cohort progression. The NLME model indicated that sub-adults hid within the reef particularly at the end of the dry season, and were most exposed on the reef surface most at the end of the wet season.

Since the numbers of sub-adults were related positively to cloud cover and inversely to air temperature, their movement onto the reef surface appears to be influenced by heat stress. Indeed, both sub-adults and adults seek shaded sides of intertidal boulders (Colquhoun 2001). Heat stress would be particularly significant in the Kimberley region of WA, where air temperatures can exceed $40^{\circ} \mathrm{C}$. Such forcing factors may be less relevant on island reefs in the Pacific with lower daily temperatures. We acknowledge that the patterns of visibility on the reef surface could be due to ecological factors, auto-correlated with temporal patterns of air temperature or cloud cover. Adults showed no seasonality in visibility on reefs, either indicating greater tolerances to heat stress than sub-adults, or that they become too large to refuge in the small holes in the reef matrix.

\section{Modelling enhancement}

Only recently have mixed-effects models been applied in marine ecology (Lewis 1997, 1998, Millar et al. 1999, Cheng \& Kuk 2002, Kimmel \& Roman 2004, Lai \& Helser 2004, Smith \& Rago 2004). Mixed-effects models are a flexible and powerful tool for analysis of repeated measures data and when experimental designs include random effects, such as blocks replicated across sites or times, or variation among individuals or time periods (Bolker et al. 2009). NLME models are useful where some of the fixed and/or random effects occur nonlinearly in the response function (Pinheiro 1994). NLME models are often mechanistic, i.e. they are based on a model for the mechanism producing the response, and the model parameters have a natural physical interpretation (Pinheiro \& Bates 2000). The analysis approach of the present study allowed a rigorous test of stocking effects, and modelled the seasonality in surface foraging in sub-adult trochus, but frequent temporal replication is needed. NLME models can incorporate known characteristics of the data, such as a periodicity of $12 \mathrm{mo}$ for estimates of sub-adult trochus abundance. Thus the NLME model used here can be considered semimechanistic (Pinheiro \& Bates 2000). The model employed in the present study estimated the enhancement effect across reefs, so this approach examines the average effect, using sites as replicates.

Mixed-effects models generally use fewer parameters than a competitor linear model, giving a simpler description of the data (Pinheiro \& Bates 2000). They are advantageous for ecological studies because they can be tailored to the specific temporal, spatial and ecological traits of the focal species. On the other hand, this flexibility necessitates computational involvement by the analyst to determine the most appropriate model (Pinheiro \& Bates 2000, Bolker et al. 2009). The outputs depend to some extent on the model chosen, but procedures are still required to formally select and criticize models (Lindstrom \& Bates 1990). Markrecapture methods are superior for stocking studies, since they circumvent the need for control sites. However, the present study shows that BACI designs and NLME models can be an alternative approach for assessing the first step in population restocking of siteattached invertebrates that cannot be tagged.

\section{CONCLUSIONS}

Trochus of BSW $<25 \mathrm{~mm}$ were not found on the reef surface in King Sound and evidence suggests these juveniles hide in holes within the reef matrix, probably to avoid predation or stressful environmental conditions. The NLME model provided a rigorous test of stocking success superimposed on a cyclical pattern through the year of their visibility on upper reef surfaces. The large variation in stocking effect among reefs suggests that multiple sites should be employed in restocking programs. The release of tiny hatcheryproduced juveniles can produce a statistically significant enhancement of local trochus stocks. However, at this experimental scale, few animals survived to subadult size to later constitute dense adult breeding populations. Further improvements to stocking methodology are needed to make this a cost-effective option for broad-scale restocking.

Acknowledgements. We thank C. Lee for project development and comments on the manuscript, which were also provided by N. Caputi, G. Maquire, J. McKinlay, B. Molony and 4 anonymous reviewers. For field assistance, we especially thank J. Colquhoun and the many volunteers: D. Ah-Choo, M. Baer, J. Fong, B. Fraser, W. Hulands, D. Lawson and K. Mortimer. Many thanks also to M. Rowe and B. Sharpe for hatchery work to culture the juvenile trochus. Additional logistic support provided by the Aboriginal communities at One Arm Point (Bardi) and Cunningham Point (Gudumul) is greatly appreciated. The project was supported by funding from the 
Australian Centre for International Agricultural Research through extension project FIS/94/10, the Department of Fisheries WA, the Aquaculture Development Fund WA, Coastcare and the Aboriginal and Torres Strait Islander Commission.

\section{LITERATURE CITED}

Akaike H (1974) A new look at statistical model identification. IEEE Trans Automat Contr 19:716-722

> Arnold WS (2008) Application of larval release for restocking and stock enhancement of coastal marine bivalve populations. Rev Fish Sci 16:65-71

Bartlett CY, Manua C, Cinner J, Sutton S and others (2009) Comparison of outcomes of permanently closed and periodically harvested coral reef reserves. Conserv Biol 23: 1475-1484

Bartley D, Bell JD (2008) Restocking, stock enhancement and sea ranching: arenas of progress. Rev Fish Sci 16:357-365

Bell JD, Rothlisberg PC, Munro JL, Loneragan NR, Nash WJ, Ward RD, Andrew NL (eds) (2005) Restocking and stock enhancement of marine invertebrate fisheries. Adv Mar Biol 49:1-370

Bell JD, Leber KM, Blankenship LH, Loneragan NR, Masuda $R$ (2008) A new era for restocking, stock enhancement and sea ranching of coastal fisheries resources. Rev Fish Sci 16: $1-9$

Blankenship HL, Leber KM (1995) A responsible approach to marine stock enhancemen. Am Fish Soc Symp 15:167-175

Bolker BM, Brooks ME, Clark CJ, Geange SW, Poulsen JR, Stevens MHH, White JSS (2009) Generalized linear mixed models: a practical guide for ecology and evolution. Trends Ecol Evol 24:127-135

Booth JD, Cox O (2003) Marine fisheries enhancement in New Zealand: our perspective. NZ J Mar Freshw Res 37 : 673-690

Castell LL (1996) Ecology of wild and cultured juvenile Trochus niloticus relevant to the use of juveniles for population enhancement. PhD thesis, James Cook University, Townsville

> Castell LL (1997) Population studies of juvenile Trochus niloticus on a reef flat on the north-eastern Queensland coast, Australia. Mar Freshw Res 48:211-217

Castell LL, Naviti W, Nguyen F (1996) Detectability of cryptic juvenile Trochus niloticus Linnaeus in stock enhancement experiments. Aquaculture 144:91-101

Cheng YW, Kuk AYC (2002) Determination of the unknown age at first capture of western rock lobsters (Panulirus cygnus) by random effects model. Biometrics 58:459-462

Clarke PJ, Komatsu T, Bell JD, Lasi F, Oengpepa CP, Leqata J (2003) Combined culture of Trochus niloticus and giant clams (Tridacnidae): benefits for restocking and farming. Aquaculture 215:123-144

Colquhoun JR (2001) Habitat preferences of juvenile trochus in Western Australia: implications for stock enhancement and assessment. SPC Trochus Inf Bull 7:14-20

- Crowe TP, Lee CL, McGuinness KA, Amos MJ and others (2002) Experimental evaluation of the use of hatcheryreared juveniles to enhance stocks of the topshell Trochus niloticus in Australia, Indonesia and Vanuatu. Aquaculture 206:175-197

Dobson G (2000) Assessing and limiting predation and other sources of mortality in reseeded Trochus niloticus. MSc thesis, Northern Territory University, Darwin

Hamasaki K, Kitada S (2008) The enhancement of abalone stocks: lessons from Japanese case studies. Fish Fish 9: $243-260$
Heasman MP (2006) In pursuit of cost-effective fisheries enhancement of New South Wales blacklip abalone, Haliotis rubra (Leach) fishery. J Shellfish Res 25:211-224

Heppell SS, Crowder LB (1998) Prognostic evaluation of enhancement programs using population models and life history analysis. Bull Mar Sci 62:495-507

Hilborn R (1998) The economic performance of marine stock enhancement projects. Bull Mar Sci 62:661-674

Hurvich CM, Tsai CL (1989) Regression and time series model selection in small samples. Biometrika 76:297-307

Isa J, Kubo H, Murakoshi M (1997) Mass seed production and restocking of trochus in Okinawa. In: Information Section of the SPC Fisheries Programme (eds) Workshop on trochus resource assessment, management and development. South Pacific Commission, Noumea, p 75-99

Jones RH (1981) Fitting continuous-time autoregressions to discrete data. In: Findley DF (ed) Applied time series analysis II. Academic Press, New York, p 651-682

Jones RH, Boadi-Boateng F (1991) Unequally spaced longitudinal data with $\mathrm{AR}(1)$ serial correlation. Biometrics 47: 161-175

Kimmel DG, Roman MR (2004) Long-term trends in mesozooplankton abundance in Chesapeake Bay, USA: influence of freshwater input. Mar Ecol Prog Ser 267:71-83

Lai HL, Helser T (2004) Linear mixed-effects models for weight-length relationships. Fish Res 70:377-387

Leber K (1999) Rationale for an experimental approach to stock enhancement. In: Howell BR, Moksness E, Svåsand $\mathrm{T}$ (eds) Stock enhancement and sea ranching. Fishing News Books, Oxford, p 63-75

Lee CL (1997a) Design and operation of a land-based closed recirculating hatchery system for the topshell, Trochus niloticus, using treated bore water. In: Lee CL, Lynch PW (eds) Trochus: status, hatchery practice and nutrition. ACIAR Proceedings No. 79, ACIAR, Canberra, p 27-32

Lee CL (1997b) ACIAR Trochus Reseeding Research Project: a simplified method of induced spawning in trochus. SPC Trochus Inf Bull 5:37-39

- Lewis AR (1997) Effects of experimental coral disturbance on the structure of fish communities on large patch reefs. Mar Ecol Prog Ser 161:37-50

Lewis AR (1998) Effects of experimental coral disturbance on the population dynamics of fishes on large patch reefs. J Exp Mar Biol Ecol 230:91-110

> Lincoln-Smith MP, Pitt KA, Bell JD, Mapstone BD (2006) Using impact assessment methods to determine the effects of a marine reserve on abundances and sizes of valuable tropical invertebrates. Can J Fish Aquat Sci 63:1251-1266

Lindstrom ML, Bates DM (1990) Nonlinear mixed-effects models for repeated measures data. Biometrics 46: 673-687

Magro KL (1997a) Catch history of trochus in King Sound, northwestern Australia between 1980 and 1995. In: Lee CL, Lynch PW (eds) Trochus: status, hatchery practice and nutrition. ACIAR Proceedings No. 79, ACIAR, Canberra, p 131-142

Magro KL (1997b) Estimating the total habitat and biomass of trochus in King Sound, northwestern Australia. In: Lee CL, Lynch PW (eds) Trochus: status, hatchery practice and nutrition. ACIAR Proceedings No. 79, ACIAR, Canberra, p 143-149

Millar RB, McArdle BH, Harley SJ (1999) Modeling the size of snapper (Pagrus auratus) using temperature-modified growth curves. Can J Fish Aquat Sci 56:1278-1284

Molony BW, Lenanton R, Jackson G, Norris J (2003) Stock enhancement as a fisheries management tool. Rev Fish Biol Fish 13:409-432 
Munro JL, Bell JD (1997) Stock enhancement of marine fisheries resources. Rev Fish Sci 5:185-222

Murphy DC, Walton WC, Roberts S, Walton BA (2005) Experimental use of bay scallop, Argopecten irradians irradians, pediveligers in restoration. J Shellfish Res 24:668-669 (Abstract)

Nash WJ (1993) Trochus. In: Wright A, Hill L (eds) Nearshore marine resources of the South Pacific. Institute for Pacific Studies, Suva, p 451-496

Pinheiro JC (1994) Topics in mixed effects models. PhD thesis, University of Wisconsin, Madison

Pinheiro JC, Bates DM (2000) Mixed-effects models in S and S-Plus. Springer-Verlag, New York

Prince JD, Sellers TL, Ford WB, Talbot SR (1988) Recruitment, growth, mortality and population structure in a southern Australian population of Haliotis rubra (Mollusca: Gastropoda). Mar Biol 100:75-82

Purcell SW (2001) Successful cage design for intermediate culture of trochus for restocking. SPC Trochus Inf Bull 8: $4-7$

Purcell SW (2002) Intertidal reefs under extreme tidal flux in Buccaneer Archipelago, Western Australia. Coral Reefs 21:191-192

Purcell SW (2004) Management options for restocked trochus fisheries. In: Leber KM, Kitada J, Blackenship HL, Svåsand $\mathrm{T}$ (eds) Stock enhancement and sea ranching: developments, pitfalls and opportunities. Blackwell Scientific, London, p 233-243

Purcell SW, Amos MJ, Pakoa K (2004) Releases of cultured sub-adult Trochus niloticus generate broodstock for fishery replenishment in Vanuatu. Fish Res 67:329-333

Editorial responsibility: Hans Heinrich Janssen, Oldendorf/Luhe, Germany
Roberts RD, Keys EF, Prendeville G, Pilditch CA (2007) Viability of abalone (Haliotis iris) stock enhancement by release of hatchery-reared seed in Malborough, New Zealand. J Shellfish Res 26:697-703

Schiel DR (1993) Experimental evaluation of commercialscale enhancement of abalone Haliotis iris populations in New Zealand. Mar Ecol Prog Ser 97:167-181

Schwarz G (1978) Estimating the dimension of a model. Ann Stat 6:461-464

Shepherd SA, Preece PA, White RWG (2000) Tired nature's sweet restorer? Ecology of abalone (Haliotis spp.) stock enhancement in Australia. Publ Spec Can Sci Halieut Aquat 130:84-97

Smith BD (1987) Growth rate, distribution and abundance of the introduced topshell Trochus niloticus Linnaeus on Guam, Mariana Islands. Bull Mar Sci 41:466-474

Smith SJ, Rago P (2004) Biological reference points for sea scallops (Placopecten magellanicus): the benefits and costs of being nearly sessile. Can J Fish Aquat Sci 61: $1338-1354$

Tegner MJ, Breen PA, Lennert CE (1989) Population biology of red abalones, Haliotis rufescens, in southern California and management of the red and pink, $H$. corrugata, abalone fisheries. Fish Bull 87:313-339

> Uki N (2006) Stock enhancement of the Japanese scallop Patinopecten yessoensis in Hokkaido. Fish Res 80:62-66

> Underwood AJ (1992) Beyond BACI: the detection of environmental impacts on populations in the real, but variable, world. J Exp Mar Biol Ecol 161:145-178

> Vermeij GJ (1976) Interoceanic differences in vulnerability of shelled prey to crab predation. Nature 260:135-136

Submitted: May 28, 2009; Accepted: April 9, 2010

Proofs received from author(s): May 22, 2010 